\title{
Educational and Vocational Aspirations of Minority and Female Students: A Longitudinal Study
}

\author{
Wei-Cheng Mau and Lynette Heim Bikos
}

\begin{abstract}
This study examined the relative importance of school, family, personal/psychological, race, and sex variables in predicting educational and vocational aspirations. A nationally representative sample of 10th-grade students was followed through 2 years beyond their high school. Results suggested that sex and race significantly predicted educational and vocational aspirations of students. The educational aspiration model was shown to be more robust than the occupational aspiration model. Overall, students showed increases in educational and occupational aspirations, regardless of sex and race. Compared with other groups, Asian Americans had the greatest increase in educational aspirations. Female students, on the average, had higher educational and vocational aspirations.
\end{abstract}

Most researchers agree that the educational goals and vocational aspirations of high school students are among the most significant predictors of eventual educational attainment (e.g., Gottfredson, 1981; Marjoribanks, 1985) and vocational attainment (e.g., Blau \& Duncan, 1967; Burke \& Hoelter, 1988; Marini, 1978; Otto \& Haller, 1979; Sewell, Haller, \& Strauss, 1957). Because of the critical nature of students' aspirations, research has turned toward determining the relative value and importance of the various factors theorized to determine and shape those specific aspirations. A variety of concerns have been subjected to empirical analysis. Examples of these variables include personal and psychological characteristics (Betz \& Hackett, 1983; Fouad \& Smith, 1996; Lent, Brown, \& Larkin, 1986), family background (Sewell \& Hauser, 1980; Singh et al., 1995; Wil-son \& Wilson, 1992), school experiences (Braddock \& Dawkins, 1993; Hossler \& Stage, 1992; Marjoribanks, 1985), gender (Dunne, Elliott, \& Carlsen, 1981; Farmer, 1985; Mau, 1995), and race (Hanson, 1994; Mau, 1995, 1997).

Although the research on high school students' educational and vocational aspirations has been substantial, the studies have drawbacks. Arguing that results cannot be generalized to women and to individuals from other ethnic groups and cultural backgrounds, several researchers have faulted previous findings that were based predominantly on samples of White men (Burke \& Hoelter, 1988; Hackett, Lent, \& Greenhaus, 1991; Hanson, 1994). In addition, al-though considerable progress has been made in examining gender issues (Astin, 1984; Farmer, 1985; Hackett \& Betz, 1981; Peterson \& Wilson, 1993), the same progress cannot be cited regarding racial-ethnic minority groups (Richardson, 1993). Finally, Farrell, Sapp, Johnson, and Pollard (1994) have suggested that although research has supported the variety of factors that influence the aspirations of high school students, the articulation among specific variables and their relative importance has not been determined.

The purpose of this study was to examine how four clusters of variables (i.e., personal/psychological characteristics, school, family variables, sex, and race) predicted (a) students' aspirations of pursuing a bachelor's degree or higher, and (b) pursuing professional occupations. Specifically, this study responded to identified weaknesses of previous re-search by (a) using a theoretical framework to guide variable selection, (b) using a longitudinal sample that was large and representative of high school students nationwide, and (c) expanding the research on race and sex differences as predictors of aspirations.

The selection of variables for this study was, in part, guided by the social cognitive theory of career and academic interest, choice, and performance (Lent, Brown, \& Hackett, 1994). This model is concerned with the effects of self-efficacy beliefs, expected outcome and goal mechanisms, and how these variables interrelate with gender, con-textual, experiential, and learning factors. In addition, the selection of 
variables was guided by the status attainment model (Blau \& Duncan, 1967; Sewell, Haller, \& Portes, 1969), which proposes that family and cognitive variables affect social psychological processes, which in turn affect educational and then occupational attainment.

Four clusters of variables were chosen for this study: psychological variables, family variables, school variables, sex, and race. What follows is a review of the findings related to these four clusters of variables. It should be noted that several previous studies (Farrell \& Pollard, 1987; Mau, 1995; Shepard, 1992; Wilson \& Wilson, 1992) have used procedures that incorporate a variety of variables or clusters of variables in their statistical analysis.

\section{Psychological Variables}

Results of previous research on the relationship between psychological variables and high school students' educa-tional and vocational aspirations have found that, compared with students with lower aspirations, students with higher aspirations were more likely to have higher self-esteem (Lay \& Wakstein, 1985; Mau, 1995), a higher self-concept (Car-penter \& Western, 1982), and an internal locus of control (Mau, 1995). Moreover, these students were more likely to place more importance on having a high status job and spent more time thinking about their post-high-school plans (Shepard, 1992).

\section{Family Variables}

Parents' expectations for their children has received much attention in the literature on high school students' educational and occupational aspirations. Although most have agreed that perceived parental expectations are positively correlated with the students' aspirations (Conklin \& Dailey, 1981; Farrell \& Pollard, 1987; Mau, 1995; Shepard, 1992; Smith, 1991; Wilson \& Wilson, 1992), there have been different interpretations of these results. For example, Wilson and Wilson reported that maternal aspirations for the high school student may have the greatest impact on the student's aspirations. Smith claimed that the student's agreement with the parental expectations was positively correlated with (and had the greatest effect on) his or her own aspirations. Shepard found that positive change in parental expectations over a 2-year period (from 9th to 11th grades) had a greater effect on students' aspirations than those parental expectations that did not change. Finally, Farrell and Pol-lard have found that the positive influence of aspirations or expectations is not limited to parents. That is, expectations by other significant people were positively related to student aspirations.

Research has also focused on the educational and financial status of the parents and on the household in general. Findings have concluded that high school students' aspirations are positively associated with the family's socioeconomic status (Farrell \& Pollard, 1987; Mau 1995), the father's occupational status (Smith, 1991), and the educational level of the parents (Wilson \& Wilson, 1992). Finally, research has indicated that students in families with fewer siblings (Mau, 1995) and students whose parents place importance on having a day job (Shepard, 1992) were more likely to have higher expectations.

\section{School Variables}

Variables related to school performance (Farrell \& Pol-lard, 1987; Harris, 1970) seem to have had a substantial effect on high school students' educational and occupational aspirations. Specific measures of these variables have included grade point average (Mau, 1995); change in grade point average over 2 years (Shepard, 1992); reading, science, and mathematics proficiency (Mau, 1995); and eighth-grade mathematics ability (Braddock \& Dawkins, 1993). Other research has indicated that aspects of the school's environment (Marjoribanks, 1985; Wilson \& Wilson, 1992) and the perceived teachers' aspirations for adolescents (Wilson \& Wilson, 1992) have also influenced students' aspirations. 


\section{Sex and Race Variables}

Results of studies examining the effects of sex and race on high school students' educational and vocational aspirations have been mixed. In a 10-year study, Hauser and Anderson (1991) found no significant differences in the aggregate trends in the aspirations of Black and White seniors. This contrasts with Wilson and Wilson's (1992) conclusion that Black adolescents had higher aspirations than their White counterparts did and that male adolescents had significantly higher aspirations than female adolescents did.

Mau (1995) reported significant main effects and inter-action effects for sex and race. Specifically, he indicated that Asian American students had significantly higher educational aspirations than any other race-based grouping of students and that Native American students had significantly lower aspirations. Black and White male students had significantly higher aspirations than did Hispanic and Native American male students. For each racial-ethnic group, female students had significantly higher educational aspirations than did their male counterparts.

Perhaps the most compelling evidence regarding the effect of sex or race on the educational and vocational aspirations of high school students has been its tendency to inter-act with other variables. Regarding psychological variables, Lay and Wakstein (1985) reported that self-esteem was more potent than actual achievement in influencing the aspirations of Black students. Carpenter and Western (1982) indicated that for men self-concept was one of the better predictors of college aspirations.

Many researchers have reported on interactions between race or sex and family variables as they affect educational and vocational aspirations. Mau (1995) found that Asian American boys and girls perceived significantly higher pa-rental expectations than did any other male group and that Native American boys and girls perceived lower expectations than did any other male group.

Smith (1991) reported a statistical interaction between race and year in school regarding students' educational expectations and goals. Beginning in early adolescence, Black students became less inclined to adopt parental educational goals, whereas White students' inclinations to adopt such goals remained the same or increased slightly.

In an attempt to develop causal models of occupational and educational expectations of 12thgrade students, Hout and Morgan (1975) concluded that White male adolescents' educational expectations were most influenced by their peers, parents, and intelligence, whereas White female adolescents were most influenced by parental encouragement. Black male adolescents were influenced by parents' encouragement, grades, and father's occupation, whereas Black female adolescents were most influenced by parents' and friends' influence, as well as the head of household's education, intelligence, and grades.

Finally, race and sex variables have had interactions with school variables. Mau (1995) reported that although educational aspirations were significantly associated with tested proficiencies in mathematics, reading, and science, the degree of association was stronger for Asian American and White student groups than it was for the Hispanic, Black American, and Native American groups of students.

In this study, we sought to determine the predictive power of four clusters of variables (e.g., personal/psychological characteristics, family variables, school variables, sex and race) on the educational and occupational aspirations of high school students. We were especially interested in examining the unique contributions of race and sex in the prediction model. We expected that race and sex would significantly improve the fit of the model. We also wanted to evaluate the strength of educational and occupational aspirations as students progressed through and 2 years be-yond their high school educational program and to evaluate any potential differences in those aspirations as a function of race and sex. 


\section{Method \\ Sample}

The data were based on the National Educational Longitudinal Study: 1988-94 (NELS:88-94; National Center for Education Statistics, 1996), third follow-up. The third follow-up sample consists of students who participated in the base year (1988), first follow-up (1990), second follow-up (1992), and third follow-up (1994) longitudinal surveys. NELS:88 was designed to "provide trend data about critical transitions experienced by students as they leave elementary school and progress through high school and into college or their careers" (National Center for Education Statistics [NCES], 1990, p. 5). The base year survey comprises a nationally representative sample of 24,599 students, selected from 1,052 middle schools (public, $n=815$, and private, $n=237$ ) in the United States. The base year sample was refreshed with additional students in both the first follow-up (10th grade, $n=20,840$ ) and second follow-up (12th grade, $n=21,188$ ). The third follow-up took place in the spring of 1994 , when most sample members had been out of high school for 2 years. The third follow-up sample consisted of 14,915 participants (boys = 7,350 , girls $=7,565$ ).

Because of sample refreshing, the third follow-up sample is constituted of a nationally representative sample of spring term 1990 sophomores and spring term 1992 seniors. The sample was stratified by school size, urban versus rural, region, and percentage of minority populations (NCES, 1994). Because of the oversampling of Hispanic and Asian Pacific Islander students, sample weights were used to reduce the oversampling bias.

\section{Variables}

Dependent variables. Two dependent variables selected for this study were (a) college aspirations and (b) occupational expectations. College aspirations were indicated by a sur-vey question: "As things stand now, how far in school do you think you will go?" Responses were classified into two dummy categories: non-college aspiration and college and beyond aspiration. Occupational aspirations were measured by a survey question: "Which occupation do you expect or plan to have when you are 30 years old?" Responses were sorted into three categories: unskilled-semiskilled, technical-semiprofessional, and professional.

Independent variables. Four clusters of independent variables were included:

1. Psychological: self-esteem ( 7 items; e.g., "I feel good about myself"), locus of control ( 6 items; e.g., "I don't have enough control over the direction my life is taking"), and academic self-efficacy (4 items; e.g., "Math is one of my best subjects," "English is one of my best subjects").

2. Family: perceived parental expectation, socioeconomic status (a composite score of parent's education, occupation and family income, compiled by the NCES), parental school involvement (7 items; e.g., "how often students have discussed selecting courses or programs at school with parents"), parental academic involvement (4 items; e.g., "how often parents attend a school meeting"), and number of siblings.

3. School: academic proficiency (measured by a composite score of a 21-item reading and a 40item math proficiency test developed by Educational Testing Services), academic program (general, academic, and vocational/technical program), school setting (urban, suburban, and rural), school size, and school type (public or private/religious schools). Except academic proficiency, all school variables were coded as dummy variables.

4. Sex and Race: Both race and sex were dummy variables.

\section{Data Analysis}

Given the dichotomous nature of the dependent variables, logistic regression models were used. Logistic regression analysis has advantages over other multivariate techniques (e.g., discriminant or multiple regression analyses) because it permits violation of normality and it is interpretable in terms of 
probability. Logistic analyses were conducted to identify those variables that predict between students who aspired to (a) bachelor's degree versus non-bachelor's degree and (b) professional versus nonprofessional occupations. As stated earlier, the variable selection and entry into the model were guided by the Status Attainment model and the social cognitive theory of career choice and aspiration. Predictors were entered in blocks using a forward stepwise method, with school variables entered first, followed by family variables, psychological variables, and sex and race. The order of entry within each cluster is deter-mined by the stepwise selection procedure. The analyses were based on weighted samples created to adjust for the oversampling bias, which redistributed the observations to represent the distribution in the population (NCES, 1997). This was done by dividing the panel weights (f3pnlwt) by the average weight. Design effects were also used to adjust standard error for hypothesis testing. Race and sex differences in educational and vocational aspirations for three longitudinal surveys were analyzed using repeated measure ANOVA 3(time) $\times 4$ (race) $\times 2$ (sex).

\section{Results}

Logistic multiple regression analyses of college aspirations were based on 6,133 (2,889 men, 3,244 women) cases; cases with missing data on any of the selected variables were not included. The race composition was 516 Asian, 637 His-panic, 432 Black, and 4,548 White Americans. Results of logistic analyses showed significant improvement of the fit of the model when the school $\left(x^{2}=1490.38, p<.000\right)$, family $\left(x^{2}=395.28, p<.000\right)$, and psychological variables $2=25.73, p<.000$ ) were added. Of special interest were the effects of sex and race, these were entered last in the model. Significant improvement was found after their addition $\left(x^{2}=43.27, p<.000\right)$. The effect of individual predictors on the level of aspiration is summarized in Table 1 . The regression coefficients $(\beta)$ given in the table are of utmost importance. The greater the $\beta$ coefficient, the more predicting power it has. A negative sign indicates that it is more likely for the students in that category to have low aspiration, whereas a positive sign indicates an increased likelihood that students in that category have high aspirations. As can be seen in Table 1, academic high school pro-gram, school type, and socioeconomic status were among the best predictors before sex and race entered the model, whereas school size, school setting, math self-efficacy, and personal self-concept were insignificant predictors. The predictive ability of the model is estimated through the probability of classification of respondents. This educational aspiration model had a correct classification rate of $83 \%$.

Listwise case selection resulted in a total of 5,670 (2,640 men, 3,030 women) cases used for logistic analyses of occupational aspirations. The composition of the sample was 475 Asian, 583 Hispanic, 404 Black, and 4,208 White Americans. Results of logistic analyses indicated significant improvement of the model's fit when the school $\left(x^{2}=672.38, p<.000\right)$, family $\left(x^{2}=113.08, p<.000\right)$, and psychological variables $\left(x^{2}=49.91, p<.000\right)$ were added. Race and $\operatorname{sex}\left(x^{2}=105.45, p<.000\right)$ were entered last into the equation and led to a significant improvement of the pre-diction. The three strongest predictors before sex and race entered the model were the following: enrolled in an academic program, public school (negative prediction), and enrolled in a general educational program (see Table 2). School setting, parental school involvement, and sibling size were not entered in the equation because of their insufficient contributions. Math self-efficacy and personal self-concept were not significant predictors in the model. This occupational aspiration model had a $72 \%$ correct classification rate. The model's goodness-of-fit has a nonsignificant likelihood ratio value that suggests an adequate fit of the model $\left(x^{2}=7.59, p<.475\right)$. 
TABLE 1

Logistic Multiple Regression Analysis of Educational Aspirations

\begin{tabular}{lcccc}
\hline \hline Variable & $\beta$ & $\boldsymbol{d f}$ & $\boldsymbol{p}$ & $\boldsymbol{R}$ \\
\hline School size & 0.086 & 1 & .165 & .045 \\
High school program & & 2 & .000 & .158 \\
$\quad$ General & 0.279 & 1 & .001 & .034 \\
$\quad$ Academic & 1.129 & 1 & .000 & .140 \\
School type & -0.945 & 1 & .025 & -.061 \\
School setting & & 2 & .157 & .022 \\
$\quad$ Urban & 0.166 & 1 & .267 & .000 \\
$\quad$ Suburban & 0.220 & 1 & .054 & .030 \\
Academic proficiency & 0.063 & 1 & .000 & .185 \\
Socioeconomic status & 0.635 & 1 & .000 & .148 \\
Parental expectations & 0.329 & 1 & .000 & .162 \\
Personal involvement & 0.094 & 1 & .000 & .064 \\
Personal self-concept & 0.051 & 1 & .414 & .000 \\
Locus of control & 0.155 & 1 & .000 & .023 \\
Math self-efficacy & 0.017 & 1 & .983 & .000 \\
English self-efficacy & 0.030 & 1 & .000 & .005 \\
Race & & 3 & .000 & .086 \\
$\quad$ Asian American & 0.826 & 1 & .006 & .042 \\
Hispanic American & 0.622 & 1 & .000 & .061 \\
Black & 0.696 & 1 & .000 & .064 \\
\hline
\end{tabular}

Table 3 provides means and standard deviations of educational and occupational aspirations by sex and race. Results of a repeated measure multivariate test of occupational aspirations indicated significant differences for Time, $F(2,7,389)=16.34, p<.000$; Time $\times$ Race, $F(6,14,780)=3.39, p<.002$, and Time $x$ Race $x$ Sex, $F(6,14,778)=2.50, p<.020$. Using a conservative approach (NCES, 1997), the $F$ values were divided by a design effect of 3 . The time factor remained statistically significant; tests of within-subjects contrasts showed a significant difference between 10th grade and 12th grade, $F(1,7,390)$ $=8.50, p<.001$. There were no significant race or sex differences between 10th grade and 12th grade or between 12th grade and the third follow-up ( 2 years beyond high school). Tests of between-subject contrasts indicated significant differences in race, $F(3,7,390)=4.09, p<.01$, and sex, $F(1,7,390)=29.17$, $p<.001$. Asian American students had the highest college aspirations, whereas Hispanic students had the lowest aspirations. Female students had significantly higher occupational aspirations than did male students.

TABLE 2

Logistic Multiple Regression Analysis of Occupational Aspirations

\begin{tabular}{lrrrr}
\hline \hline Variable & $\beta$ & $\boldsymbol{d f}$ & $\boldsymbol{p}$ & $\boldsymbol{R}$ \\
\hline School size & .056 & 1 & .003 & .032 \\
High school program & & 2 & .000 & .075 \\
$\quad$ General & .375 & 1 & .000 & .043 \\
$\quad$ Academic & .641 & 1 & .000 & .074 \\
School type & .517 & 1 & .000 & -.048 \\
Academic proficiency & .041 & 1 & .000 & .122 \\
Socioeconomic status & .207 & 1 & .000 & .050 \\
Parental expectations & .203 & 1 & .000 & .090 \\
Personal self-concept & -.019 & 1 & .736 & .000 \\
Locus of control & .233 & 1 & .000 & .042 \\
Math self-efficacy & -.019 & 1 & .122 & -.008 \\
English self-efficacy & .046 & 1 & .008 & .027 \\
Men & -.601 & 1 & .000 & -.116 \\
Race & & 3 & .016 & .026 \\
$\quad$ Asian American & .391 & 1 & .021 & .022 \\
Hispanic American & .153 & 1 & .199 & .000 \\
Black & .271 & 1 & .023 & .022 \\
\hline
\end{tabular}

Note. School setting, parental school involvement, and sibling size were not included in the equtions due to an insignificant contribution. 
Multivariate tests indicated significant differences in college aspirations for the within-subjects factor, time, $F(2,10,993)=161.70, p<.000$. Tests of within-subjects contrasts indicated significant differences from 10th grade to 12th grade, $F(1,10,994)=166.89, p<.05$; and from 10th grade to postgraduation (third follow-up), $F(1,10,994)=198.38, p<.05$. Significant 10th grade and postgraduation differences also were found as a function of race, $F(3,10,994)=2.90, p<.05$. Tests of between-subjects contrasts showed significant differences in race, $F(3,10,994)=10.50, p<.001$, and sex, $F(1,10,994)=$ 8.70, $p<.01$. Post hoc Scheffé analyses indicated that Asian Americans consistently outscored other groups, whereas Hispanic Americans consistently scored significantly lower than did other groups in the 10th-grade and 12th-grade measures. Specifically, as can be seen in Table 3, Asian American students had the highest college aspirations, whereas Hispanic students had the lowest aspirations. Female students had significantly higher educational aspirations than did male students.

In sum, sex and race seemed to be significant variables in predicting the educational and vocational aspirations of high school students. The educational aspiration model was shown to be more robust than the occupational aspiration model. Overall, students showed increases in educational and occupational aspirations regardless of sex and race. Compared with other groups, Asian American students had the greatest increase in educational aspirations. Female students had higher college aspirations and occupational aspirations than did male students.

\section{Discussion}

This study examined how four clusters of variables predicted students' educational and occupational aspirations. In an attempt to avoid the pitfalls of previous studies, we used two theoretical models to provide a frame for the design of the study. The first was the Social Cognitive Model of Career Development (Lent et al., 1994), and the second was the Status Attainment Model (Blau \& Duncan, 1967; Sewell et al., 1969). In addition, we chose to use a national sample of students that included substantial representation of Hispanic, Asian, Black, and White students. Moreover, these same students were followed longitudinally for 4 years. Finally, the results and discussion of this study are directed toward articulating some sense of the relative importance of the specific variables used in the analysis.

For both educational and occupational aspirations, results of this study indicated that the clusters of school, family, and psychological variables were significant predictors. It is interesting that when these were statistically controlled the cluster of race and sex continued to predict educational and occupational aspirations. The results of our study are consistent with others (Farrell \& Pollard, 1987; Mau, 1995; Shepard, 1992; Wilson \& Wilson, 1992) that included a variety of variables and concluded that many of them influenced students' educational and occupational aspirations.

Before including race and sex in the model, the students' high school program (academic track), and school type (private school) were the two strongest predictors of both educational and occupational aspirations. Although academic proficiency is a significant predictor for both educational and occupational aspiration, it is the least predictive in the model. Our study differed from others that included school variables in that the type of high school referred to its classification as a public or private/religious school. We are not aware of other studies that have found significant differences regarding that variable. However, at least two studies (Marjoribanks, 1985; Wilson \& Wilson, 1992) have reported that aspects of school environments influence students' aspirations. Our finding that academic proficiency is related to educational and occupational aspirations is also consistent with other studies. In fact, researchers (Farrell \& Pol-lard, 1987; Harris, 1970) have suggested that those variables related to school performance have the greatest effect on high school students' aspirations. Noteworthy is that academic proficiency seemed to contribute the least to the prediction model when other school variables were considered. As expected, this study showed that parental education expectations had a high degree of influence on students' aspirations, which is in accordance with the status attainment model and other studies (Conklin \& Dailey, 1981; Farrell \& Pollard, 1987; Mau, 1995; Shepard, 1992; Smith, 1991; Wilson \& Wilson, 1992). Finally, 
consistent with the social cognitive model, the present study indicated that internal locus control was a significant predictor for both educational and occupational aspirations.

TABLE 3

Means and Standard Deviations for Educational and Occupational Aspirations by Grade, Race, and Sex

\begin{tabular}{|c|c|c|c|c|c|c|}
\hline \multirow[b]{2}{*}{ Race/Sex } & \multicolumn{3}{|c|}{ Educational Aspirations } & \multicolumn{3}{|c|}{ Occupational Aspirations } \\
\hline & $M$ & $S D$ & $n$ & $M$ & $S D$ & $n$ \\
\hline \multicolumn{7}{|c|}{ 10th Grade } \\
\hline Men & 1.66 & 0.48 & 190 & 2.56 & 0.83 & 108 \\
\hline Women & 1.73 & 0.44 & 172 & 2.78 & 0.51 & 116 \\
\hline \multicolumn{7}{|l|}{ Hispanic American } \\
\hline Men & 1.54 & 0.50 & 453 & 2.34 & 0.72 & 321 \\
\hline \multicolumn{6}{|l|}{ Black } & 328 \\
\hline Men & 1.58 & 0.48 & 735 & 2.46 & 0.73 & 455 \\
\hline Women & 1.64 & 0.48 & 772 & 2.59 & 0.71 & 555 \\
\hline \multicolumn{7}{|l|}{ White } \\
\hline Men & 1.59 & 0.48 & 4,079 & 2.41 & 0.74 & 2,732 \\
\hline Women & 1.67 & 0.47 & 4,089 & 2.63 & 0.70 & 2,783 \\
\hline \multicolumn{7}{|l|}{ Total } \\
\hline Men & 1.59 & 0.48 & 5.457 & 2.41 & 0.74 & 3,616 \\
\hline Women & 1.65 & 0.48 & 5,545 & 2.62 & 0.71 & 3,782 \\
\hline Total & 1.62 & 0.48 & 11,002 & 2.52 & 0.73 & 7,398 \\
\hline \multirow{2}{*}{\multicolumn{7}{|c|}{ Asian American }} \\
\hline & & & 180 & 2.87 & 0.58 & 108 \\
\hline Women & 1.80 & 0.40 & 172 & 2.67 & 0.63 & 118 \\
\hline \multicolumn{7}{|l|}{ Hispanic American } \\
\hline Men & 1.63 & 0.48 & 453 & 2.39 & 0.72 & 321 \\
\hline Women & 1.56 & 0.50 & 512 & 2.61 & 0.68 & 328 \\
\hline \multicolumn{7}{|l|}{ Black } \\
\hline Men & 1.63 & 0.48 & 735 & 2.35 & 0.77 & 455 \\
\hline Women & 1.74 & 0.44 & 772 & 2.61 & 0.70 & 555 \\
\hline \multicolumn{7}{|l|}{ White } \\
\hline Men & 1.64 & 0.48 & 4.079 & 2.43 & 0.71 & 2,732 \\
\hline Women & 1.68 & 0.46 & $4,089^{\circ}$ & 2.63 & 0.70 & 2,783 \\
\hline \multicolumn{7}{|l|}{ Total } \\
\hline Men & 1.64 & 0.48 & 5,457 & 2.43 & 0.72 & 3,616 \\
\hline Women & 169 & 0.46 & 5.545 & 2.83 & 0.70 & 3,782 \\
\hline Total & 1.66 & 0.47 & 11,002 & 2.53 & 0.71 & 7,398 \\
\hline \multicolumn{7}{|l|}{ Asian American } \\
\hline Men & 1.83 & 0.38 & 180 & 2.67 & 0.47 & 108 \\
\hline Women & 1.88 & 0.32 & 172 & 2.80 & 0.42 & 116 \\
\hline \multicolumn{7}{|l|}{ Hispanic American } \\
\hline Men & 1.70 & 0.46 & 453 & 2.51 & 0.57 & 321 \\
\hline Women & 1.68 & 0.47 & 512 & 2.65 & 0.57 & 328 \\
\hline \multicolumn{7}{|l|}{ Black } \\
\hline Men & 1.65 & 0.48 & 735 & 2.55 & 0.57 & 455 \\
\hline Women & 1.77 & 0.42 & 772 & 2.64 & 0.57 & 555 \\
\hline \multicolumn{7}{|l|}{ White } \\
\hline Men & 1.72 & 0.45 & 4.079 & 2.49 & 0.60 & 2,732 \\
\hline Women & 1.75 & 0.43 & 4,089 & 2.65 & 0.81 & 2,783 \\
\hline \multicolumn{7}{|l|}{ Total } \\
\hline Men & 1.71 & 0.45 & 5.457 & 2.51 & 0.59 & 3,616 \\
\hline Women & 1.75 & 0.43 & 5,545 & 2.85 & 0.60 & 3,782 \\
\hline Total & 1.73 & 0.44 & 11,002 & 2.58 & 0.60 & 7,398 \\
\hline
\end{tabular}

Note. Educational aspirations: non-college; college. Occupational aspirations: unskilled-semiskilled, technical-semiprofessional, and professional.

The logistic regression model for educational aspirations was far more robust than the occupational aspiration model. Given that these students were beginning to enter their postsecondary years, it makes sense that they might have identified specific goals for their education but were still developing the more chronologically distant occupational goals.

Although there was a trend among all students to show increases in educational aspirations, gains were statistically significant from the 10th to the 12 th grade and from the period between 12 th grade and the postgraduation follow-up. At the time of the 10th grade and postgraduation measurements, significant differences were found in race. Specifically, Asian Americans demonstrated consistently higher 
educational aspirations, and Hispanic Americans had consistently lower educational aspirations. The higher educational aspirations of Asian Americans and the lower educational aspirations for Hispanic Americans, a pattern that has been noted in other research (George, 1990; Mau, 1995), may be accounted for by experiential, learning, or cultural factors that are unique to those groups. For ex-ample, Sue and Sue (1990) noted that for Asian American students, academic success is considered a source of pride for the family. Moreover, it is perceived as an avenue for advancement when other areas are closed. In contrast, His-panic students may be recent immigrants or the children of recent immigrants. For these families, financial pressures and language difficulties may lead to premature dropout from school. Moreover, institutional racism, lack of role models, and poverty may depress the educational and vocational aspirations of these students.

In accordance with previous studies (Apostal \& Bilden, 1991; Dawkins, 1989), the present study showed that women expressed significantly higher occupational aspirations. This finding may reflect greater awareness of high level professional career opportunities for women brought about by better communication and observation of role models pro-vided by female professionals. Nevertheless, irrespective of race or sex, it seems that all students make increases in occupational aspirations. The time of greatest increase is be-tween the 10th and 12th grades. This increase is probably due to an increased level of postsecondary planning in the 2-year interim (Mau, Hitchcock, \& Calvert, 1998).

Those who advocate a social cognitive theory of career and academic development might argue that the gains we found in educational and occupational aspirations were connected to improved selfefficacy for specific training programs and occupational selections. It has been supported by previous research that self-efficacy beliefs change and grow as children age (Flammer, 1995; Zimmerman, 1995). Moreover, in these critical years, students may have clarified the expected out-comes of such training programs and career tracks and may have refined their individual career goals. It is unfortunate that there was no specific measure or self-efficacy or outcome expectations in the data set. Despite this limitation, the results of our research are highly consistent with the social cognitive model's proposition that career aspirations develop as a result of self-efficacy and outcome expectations, which are differentially mediated by demographic and individual difference variables (such as sex or race). The Social Cognitive and the Status Attainment models can be used to provide theoretical frameworks for organizing these variables in causal relationships. Future studies may examine these relationships in light of these models.

Because this study relied on general broad-based survey data, the specific questionnaire items were limited in scope and depth. For example, because there was no specific measure of self-efficacy, we used locus of control and self-esteem to represent the self-efficacy construct. In addition, some data analyses were based on one-item responses only. Thus, the interpretation of the results needs special attention. Nevertheless, this study provides some empirical support for the assumption that there was significant impact of school, family, psychological, and race and sex variables on career aspirations of students based on a nationally representative sample.

\section{Counseling Applications}

If, in practice, our goals are to increase the probability that our students realistically identify their educational and occupational aspirations and to help them complete the associated educational programs, then a thorough examination of students' school, family, and psychological background becomes essential. Counseling interventions can be developed to address the school issues (e.g., premature academic tracking, low academic proficiency), family issues (e.g., low parental expectation and involvement), and psychological issues (external locus of control, academic self-concept) for those students who have low aspirations.

Whether or not students are enrolled in an academic pro-gram seemed to be the single most predictive variable for college aspiration in the model. Students may be locked in a particular program prematurely. Counselors can help students explore their educational and vocational goals and assist them 
in planning educational programs that match their goals. Given the importance of academic proficiency for higher education, counselors could identify students who have college aspirations but are lacking in academic proficiency and help them develop strategies for achieving their goals. One mistake counselors often make is that those in the college track tend to be overemphasized, whereas those in the non-college track receive little or no attention (Hoyt, Hughey, \& Hughey, 1995). Helping students see various educational and vocational options and develop realistic goals are considered to be key elements in high school counseling programs (Mau et al., 1998).

When considering the extra barriers minority students would encounter in their education vocational pursuits, programs such as Upward Bound can be beneficial and should be used by school counselors when available and if appropriate. The Upward Bound program was created in 1965 by the United States Department of Education to encourage underprepared, economically disadvantaged students to maximize their full potential and to graduate from high school and enter postsecondary institutions. Currently, 598 Upward Bound programs exist in the United States and serve 48,412 students annually in the 9th through 12th grades. Many of these students pursue postsecondary education as a result of their involvement in Upward Bound (National Council of Educational Opportunity Associations, 1996).

Recently, O'Brien, Bikos, Flores, Dukstein, and Kamatuka (1996) reported on the development and refinement of a career component that was included in the 6-week summer institute of a local Upward Bound program. The career development component was developed using the Social Cognitive Model of Career Development (Lent et al., 1994) as its theoretical foundation. Given Upward Bound's requirement that the individual student's school and family demonstrate active commitment to and involve- ment with the program, this program is designed to have a significant effect on those variables that have been found to predict students' aspirations. In their study, O'Brien et al. (1996) reported that students participating in the ca-reer exploration programs evidenced increased confidence in performing tasks related to investigating, selecting, and implementing a career choice.

Given the predictive power of race and sex identified in this study, the next step in refining this line of research may be using structural equation modeling to create causal models of key variables for educational and occupational aspirations for groups of students identified by their race and sex. The researcher may begin by creating an overall model based on students in general and then comparing its fit with other samples of students. For those groups of students for whom the fit is unacceptable or inadequate, revisions or refinements of the model could lead to a more accurate understanding of that group.

Finally, our data suggest substantial impact of the type of high school program and socioeconomic status of the family on students' aspirations. More precise and practical results may be obtained by creating even more specific models that include these variables in the selection of the students to be included in the analysis (i.e., Asian American girls who at-tend general high school programs and are from families with a low socioeconomic status). Although this research might be painstakingly tedious and not generalizable to students in general, it could provide valuable data for creating more effective interventions for those students in a counselor's school and community.

In summary, sex and race have continued to be demonstrated as predictive of educational and occupational aspirations of high school students. This longitudinal study indicated that most students continue to increase their educational and occupational aspirations through high school and 2 years beyond high school. Data indicated that, as grouped by race, Asian Americans tend to have higher than average educational goals, and Hispanic Americans tend to have lower than average educational goals. Given the continued predictive power of race and sex, causal or structural modeling of more specific groups (e.g., identified by race, sex, and other salient factors such as socioeconomic status or type of high school program) that can be targeted for intervention, will lead to results that can lay the foundation for practice-based interventions. 


\section{References}

Apostal, R., \& Bilden, J. (1991). Educational and occupational aspiration of rural high school students. Journal of Career Development, 18, 153-160.

Astin, H. S. (1984). The meaning of work in women's lives: A sociopsychological model of career choice and work behavior. The Counseling Psychologist, 12, 117-126.

Betz, N. E., \& Hackett, G. (1983). The relationship of mathematics self-efficacy expectations to selection of science-based college majors. Journal of Vocational Behaviors, 23, 329-345.

Blau, P. M., \& Duncan, O. D. (1967). The American occupational structure. New York: Wiley.

Braddock, J. H., \& Dawkins, M. P. (1993). Ability grouping, aspirations, and attainments: Evidence from the National Educational Longitudinal Study of 1988. Journal of Negro Education, 62, 324-336.

Burke, P. J., \& Hoelter, J. W. (1988). Identity and sex-race differences in educational and occupational aspiration formation. Social Science Research, 17, 29-47.

Carpenter, P. G., \& Western, J. S. (1982). Aspirations for higher education. Australian Journal of Education, 26, 266-278.

Conklin, M. E., \& Dailey, A. R. (1981). Does consistency of parental educational encouragement matter for secondary students? Sociology of Education, 54, 254-262.

Dawkins, M. P. (1989). The persistence of plans for professional careers among Blacks in early adulthood. Journal of Negro Education, 58, 220-231.

Dunne, F., Elliott, R., \& Carlsen, S. (1981). Sex differences in educational and occupational aspirations of rural youth. Journal of Vocational Behavior, 18, 56-66.

Farmer, H. S. (1985). Model of career and achievement motivation for women and men. Journal of Counseling Psychology, 32, 363-390.

Farrell, W. C., \& Pollard, D. S. (1987). An examination of factors related to minority students' decision to attend college. Milwaukee, WI: The Graduate School, University of Wisconsin-Milwaukee.

Farrell, W. C., Sapp, M., Johnson, J. H. Jr., \& Pollard, D. S. (1994). Assessing college aspirations among atrisk high school students: A principal component analysis. The High School Journal, 77, 294-303.

Flammer, A. (1995). Developmental analysis of control beliefs. In A. Bandura (Ed.), Self-efficacy in changing societies (pp. 69-113). New York: Cambridge University Press.

Fouad, N. A., \& Smith, P. L. (1996). A test of a social model for middle school students: Math and science. Journal of Counseling Psychology, 43, 338-346.

George, C. A. (1990). Course enrollment practices of high school students in California. Sacramento, CA: California State Department of Education. (ERIC Document Reproduction Service No. ED 317 897)

Gottfredson, D. C. (1981). Black-White differences in educational attainment process: What have we learned? American Sociological Review, 46, 542-557.

Hackett, G., \& Betz, N. E. (1981). A self-efficacy approach to the career development of women. Journal of Vocational Behavior, 18, 326-339.

Hackett, G., Lent, R. W., \& Greenhaus, J. H. (1991). Advances in vocational theory and research: A 20year retrospective. Journal of Vocational Behavior, 38, 3-38.

Hanson, S. L. (1994). Lost talent: Unrealized educational aspirations and expectations among U.S. youths. Sociology of Education, 67, 159-183.

Harris, L. E. (1970). Personal and parental influences on college attendance: Some Negro-White differences. Journal of Negro Education, 39, 305-313.

Hauser, R. M., \& Anderson, D. K. (1991). Post high-school plans and aspirations of Black and White high school seniors: 1976-86. Sociology of Education, 64, 263-277.

Hossler, D., \& Stage, F. K. (1992). Family and high school experience influence on postsecondary educational plan of ninth-grade students. American Educational Research Journal, 29, 425-451.

Hout, M., \& Morgan, W. R. (1975). Race and sex variations in the causes of the expected attainments of high school seniors. American Journal of Sociology, 81, 364-394. 
Hoyt, K. B., Hughey, J. K., \& Hughey, K. F. (1995). An introduction to the "Counseling for High Skill": Voctech career options project. The School Counselor, 43, 10-18.

Lay, R., \& Wakstein, J. (1985). Race, academic achievement and self-concept of ability. Research in Higher Education, 22, 43-64.

Lent, W. L., Brown, S. D., \& Hackett, G. (1994). Toward a unifying social cognitive theory of career and academic interest, choice, and performance. Journal of Vocational Behavior, 45, 79-122.

Lent, W. L., Brown, S. D., \& Larkin, K. C. (1986). Self-efficacy in the prediction of academic performance and perceived career options. Journal of Counseling Psychology, 33, 165-169.

Marini, M. (1978). Sex differences in the determination of adolescent aspirations: A review of research. Sex Roles, 4, 723-753.

Marjoribanks, K. (1985). Families, schools, and aspirations: Ethnic group differences. Journal of Experimental Education, 53, 141-147.

Mau, W. C. (1995). Educational planning and academic achievement of middle school students: A racial and cultural comparison. Journal of Counseling \& Development, 73, 518-526.

Mau, W. C. (1997). Parental influence on the academic achievement of high school students: A comparison of Asian immigrants, Asian Americans, and White Americans. Psychology in the Schools, 34, 267277.

Mau, W. C., Hitchcock, R., \& Calvert, C. (1998). Career plans and perceived counselors' and other influential persons' expectations of high school students. Professional School Counseling, 2, 161166.

National Center for Education Statistics. (1990). National educational longitudinal study, 1988: Base year student component data file user's manual (Report No. 90-464). Washington, DC: U.S. Department of Education.

National Center for Education Statistics. (1994). National educational longitudinal study, 1988: Second follow-up (1992) (Report No. 94-374). Washington, DC: U.S. Department of Education.

National Center for Education Statistics. (1996). National educational longitudinal study: 1988-1994 files and electronic codebook system [CD-ROM]. Washington, DC: U.S. Department of Education.

National Center for Education Statistics. (1997). A note from the chief statistician: Technical approaches to performing regression and other multivariable techniques on NCES survey data (Notes No. 3). Washington, DC: U.S. Department of Education.

National Council of Educational Opportunity Associations. (1996). Congressional relations manual. Washington, DC: Author.

O’Brien, K. M., Bikos, L. H., Flores, L. Y., Dukstein, R. D., \& Kamatuka, N. A. (1996, August). A career exploration program for Upward Bound students. In K. M. O’Brien \& M. J. Heppner (Chairs), Future directions in career counseling: Innovative interventions with special populations. Symposium conducted at the 1996 National Convention of the American Psychological Association, Toronto, Canada.

Otto, L. B., \& Haller, A. O. (1979). Evidence for a social psychological view of the status attainment process: Four studies compared. Social Forces, 57, 887-914.

Peterson, G. W., \& Wilson, P. (1993). The process of educational and occupational attainment of adolescent female from low-income, rural families. Journal of Marriage and the Family, 55, 158175.

Richardson, M. S. (1993). Work in people's lives: A location for counseling psychologist. Journal of Counseling Psychology, 40, 425-433. Sewell, W. H., Haller, A. O., \& Portes, A. (1969). The educational and early occupational attainment process. American Sociological Review, 34, 89-92.

Sewell, W. H., Haller, A. O., \& Strauss, M. A. (1957). Social status and educational and occupational aspiration. American Sociological Review, 22, 67-73. 
Sewell, W. H., \& Hauser, R. M. (1980). The Wisconsin study of social psychological factors in aspiration and achievements. Research in Sociology of Education and Socialization, 1, 59-99.

Shepard, L. L. (1992, A pril). Factors influencing high school students' differences in plans for postsecondary education: A longitudinal study. Paper presented at the annual meeting of the American Educational Research Association, San Francisco.

Singh, K., Bickley, P. G., Keith, T. Z., Keith, P. B., Trivette, P., \& Ander son, E. (1995). The effect of four component of parental involvement on eighth-grade student achievement: Structure analysis of NELS-88 data. School Psychology Review, 24, 299-317.

Smith, T. E. (1991). Agreement of adolescent educational expectations with perceived maternal and paternal educational goals. Youth and Society, 23, 155-174.

Sue, D. W., \& Sue D. (1990). Counseling the culturally different: Theory and practice (2nd ed.). New York, Wiley.

Wilson, P. M., \& Wilson, J. R. (1992). Environmental influences on adolescent educational aspirations: A logistic transform model. Youth \& Society, 24, 52-70.

Zimmerman, B. J. (1995). Self-efficacy and educational development. In A. Bandura (Ed.), Self-efficacy in changing societies (pp. 202-231). New York: Cambridge University Press. 